\title{
Immunohistochemistry of Canine Hair Follicle Stem Cells (cHFSCs) by using CK15 and CK19
}

\author{
N. Hemavathi ${ }^{1}$, Sabiha Hayath Basha ${ }^{2 *}$, S. Usha Kumary ${ }^{3}$ and R. Sivashankar ${ }^{4}$ \\ ${ }^{1}$ Department of Veterinary Anatomy, Madras Veterinary College, TANUVAS, Chennai, Tamil Nadu, INDIA \\ ${ }^{2}$ Centre for Stem Cell Research and Regenerative Medicine, Madras Veterinary College, TANUVAS, Chennai, \\ Tamil Nadu, INDIA \\ ${ }^{3}$ Department of Veterinary Anatomy, Madras Veterinary College, TANUVAS, Chennai, Tamil Nadu, INDIA \\ ${ }^{4}$ Department of Veterinary Surgery and Radiology, Madras Veterinary College, TANUVAS, Chennai, Tamil Nadu, INDIA
}

"Corresponding author: SH Basha; E-mail: sabihahb@yahoo.com

Received: 05 Feb., 2020

Revised: 24 Feb., 2020

Accepted: 20 March, 2020

\begin{abstract}
Adult body harbors powerful reservoir of stem cells that maintains homeostasis by tissue regeneration and in response to disease and injury. Hair follicle is a dynamic mini organ supporting important biological functions of the body in maintaining homeostasis and skin tissue self-renewal. This study was carried out with the objective of finding the adult stem cells in canine hair follicular tissue. To conduct this study, adult canine skin samples $(n=12)$ irrespective of breed and sex were collected. To characterize the hair follicle stem cells, paraffin sections of canine hair follicles were immunostained with positive hair follicle stem cell markers like Anti- cytokeratin 15 (CK15) and Anti-cytokeratin 19 (CK19) and FITC conjugated and HRP conjugated secondary antibodies were used. Immunoreactivities for CK15 and CK19 were observed in the bulge/isthmus region of hair follicles in between the infundibulum and suprabulbar regions and occupied most part of the peripheral layer of outer root sheath cell. Immunophenotyping of canine Hair Follicle Stem Cells (cHFSCs) in the bulge region of hair follicle helps in confirmation of in vitro culture of cHFSCs from the bulge region which will be further used for translational research.
\end{abstract}

Keywords: Cytokeratin15 (CK15), Cytokeratin 19 (CK19), Hair follicle stem cells, Stem cells

Adult Stem Cells (ASC) are undifferentiated cells located throughout the body and characterized by self-renewing capacity and multipotency; these cells participated in tissue regeneration of damaged tissues and replenishment of dying cells (Maleki et al., 2014). Hair follicles contained rapidly proliferating and differentiating cells similar to other self-renewing tissues such as bone marrow, gastrointestinal tract and epidermis. The hair follicle was functioning as the "bone marrow of the skin" and continuously remodeled its cutaneous microenvironment including skin innervation and vasculature (SchmidtUllrich and Paus, 2005). According to Kobayashi et al. (1993) over 95 per cent of the keratinocyte colony forming cells isolated from rat vibrissa were located mainly in the bulge and remainder were present in the bulb region of the hair follicle. These bulge cells were quiescent throughout the hair follicle cycle but they transiently proliferated at the onset of anagen to generate rapidly proliferating progeny that regenerate a new follicle (Lyle et al., 1999).

Hair follicle stem cells (HFSCs) were characterized by expression of gene markers such as $\beta 1$ integrin, cytokeratin 15 (CK15), cytokeratin 19, $\alpha 6$ integrin, CD71, S100A, Caveolin1, CD200, PHLDA1, follistatin, frizzled homolog 1, nestin (neuron progenitor cell marker) and CD34 glycoprotein in human (Ohyama et al., 2006). The coexpression of cytokeratin 19 (CK19) (HFSCs marker) and Bcl-2 (apoptosis suppressing protein) but not Bax (apoptosis promoting protein) was observed in two distinct areas localized in upper and lower third of human hair

How to cite this article: Hemavathi, N., Basha, S.H., Kumary, S.U. and Sivashankar, R. (2020). Immunohistochemistry of canine hair follicle stem cells (cHFSCs) by using CK15 and CK19. J. Anim. Res., 10(2): 189-193. 
follicles from both skin biopsies and plucked hairs (Gho et al., 2004). The bulge region of hair follicles of canine, positively stained with CK15, CD200 and follistatin was observed in the outermost layer of the ORS between the insert point of the arrectorpili muscle and the sebaceous gland, similar to the distribution of K15 immuno-reactivity in human hair follicles (Kobayashi et al., 2010).

\section{MATERIALS AND METHODS}

Canine hair follicle samples $(n=12)$ were collected from surgical cases brought to Madras Veterinary College Teaching Hospital. Collected skin samples were rinsed in normal saline and fixed in 10 per cent neutral buffered formalin. The fixed tissues were dehydrated in ascending grades of alcohol, cleared in xylene and embedded in paraffin wax (Bancroft and Stevens, 1990). Tissue sections were cut at $3-5 \mu \mathrm{m}$ thickness and used for the routine haematoxylin-eosin staining method.

\section{Immunostaining with FITC conjugated secondary antibody}

Deparaffinized skin sections were permeabilized by $500 \mu 1$ of $0.025 \%$ triton- $100 \mathrm{X}$ in Tris Buffered Saline (TBS) for five minutes with gentle agitation in room temperature for two times. $10 \%$ goat serum was used as blocking agent for 2 hours. Sections were incubated with primary antibody Anti-Cytokeratin 15 (Cat. No. ab80522, Abcam) at $1.25 \mu \mathrm{g} / \mathrm{ml}$ concentration in $1 \% \mathrm{BSA}$ for overnight at $4^{\circ} \mathrm{C}$. Thensections werepermeabilized with triton-100 for 10 minutes and then incubated with 1:1000 dilutions of FITC conjugated secondary antibody in $1 \%$ BSA for one hour at in room temperature. Sections were counterstained by 4'6- diamino-2-phenylindole (DAPI) with fluoroshieldand mounted.

\section{Immunostaining with HRP conjugated secondary antibody}

Heat mediated antigen retrieval was done in antigen retrieval device (MERE) with antigen retrieval buffer of Tris/EDTA, with a $\mathrm{pH}$ between 8.5-9.0 for 15-20 minutes. Blocking of endogenous peroxidase was done with three per cent hydrogen peroxide for 10 minutes and washed with washing buffer. Sections were incubated with primary antibody, Anti-Cytokeratin $15(1 \mu \mathrm{g} / \mathrm{ml})$, Anti-Cytokeratin
19 in a moist chamber for one hour and polyexcel HRP conjugated secondary antibody was added and incubated for 12 minutes and sections were washed with three times in wash buffer. Diaminobenzidine (DAB) chromgen solution (1ml DAB buffer + one drop DAB chromogen) added and kept for two to five minutes and washed in distilled water. The sections were counterstained with Gill's haematoxylin.

Hair follicle stem cells were isolated and cultured from canine hair explants by using William's E medium as a growth medium supplemented with $10 \%$ fetal bovine serum, and $10 \mathrm{ng} / \mathrm{ml}$ of epidermal growth factor, $5 \mathrm{ng} / \mathrm{ml}$ of insulin growth factor, $2 \%$ ABAM and $1 \%$ amphotericin $\mathrm{B}$ in a humidified atmosphere at $37^{\circ} \mathrm{C}$ with 5 per cent $\mathrm{CO}_{2}$. Growth medium was changed every three to four days. Primary culture was maintained upto 14 days to obtain the colonies (Hemavathi et al., 2019). Colonies were immunostained with hair follicle stem cells primary antibody Anti-Cytokeratin 15 (CK15) and FITC conjugated secondary antibody.

\section{RESULT AND DISCUSSION}

Canine hair follicles were divided into four regions as bulb, supra bulb, isthmus and infundibulum from the base to outward. The hair follicle's bulb and bulge regions were well demarcated by the indentation of supra bulb region. Similar to murine hair follicles, canine hair follicle also showed eight layers in their cross sections: outer root sheath (ORS), inner root sheath (IRS), henley's layer, huxley's layer, internal layer, cuticle, cortex, medulla from outward to inwardsin their cross section (Alcolea and Jones, 2014).

Paraffin sections of the canine skin samples were immunostained with CK15 and CK19 antibodies and location of HFSCs in the hair follicle was detected. In longitudinal sections of hair follicles, the positive CK15 (Fig. 1) and CK19 cells (Fig. 2) were observed to be located above the supra bulb region of the hair follicles and defined as bulge. In human anagen hair follicle, CK19 was expressed within the bulge and suprabulbar ORS and also intermittently between these two region in the bulge region (Purba et al., 2014).

In cross sections of hair follicles, the positively stained cells for CK15 (Fig. 3) and CK19 (Fig. 4) respectively 
were found to be on the periphery of the outer root sheath of the hair follicle. The cHFSCs were located on the peripheral layer of the ORS and near the insertion point of APM, as described by Ohyama et al. (2006) in human and Kobayashi et al. (2009) in canine hair follicle.

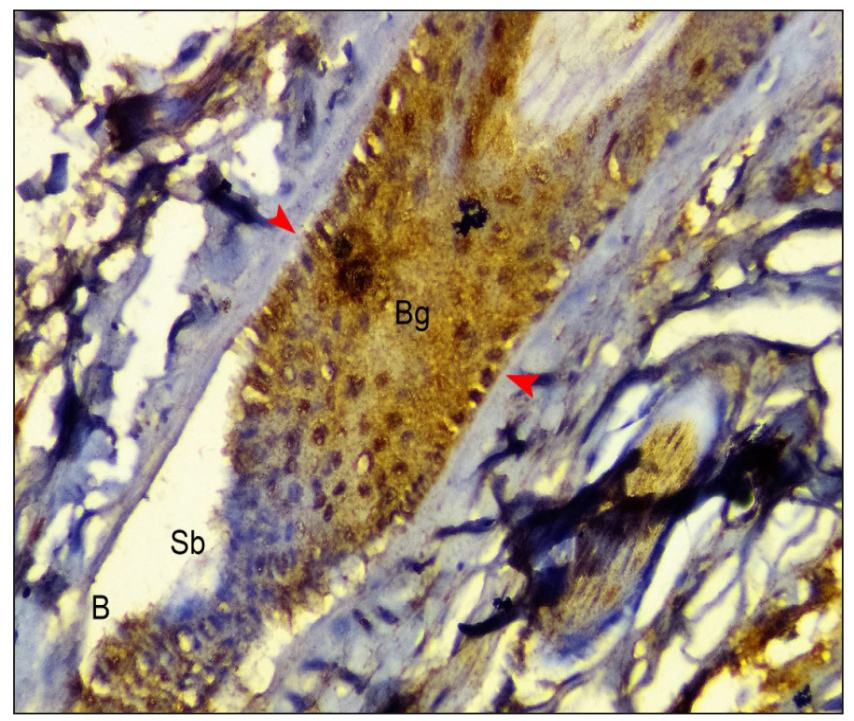

Fig. 1: Photomicrograph of longitudinal section of canine hair follicle showing Cytokeratin 15 (CK15) positively stained cells (arrowheads) at the bulge region. $\times 200$ B- Bulb Sb- SuprabulbBg- Bulge

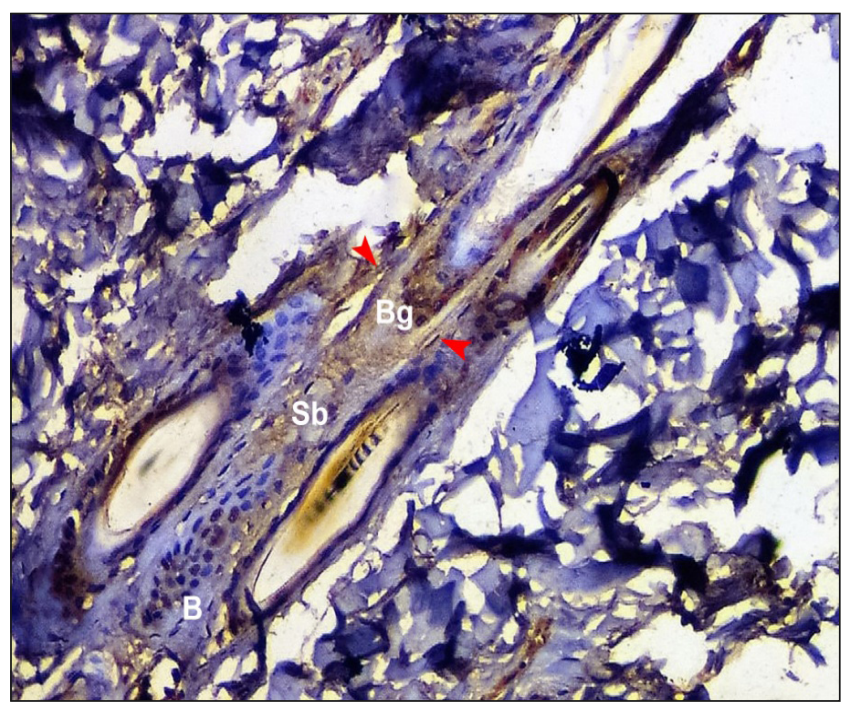

Fig. 2: Photomicrograph of longitudinal section of canine hair follicle showing Cytokeratin 19 (CK19) positively stained cells (arrowheads) at the bulge region. $\times 100$ B- Bulb Sb- SuprabulbBg- Bulge

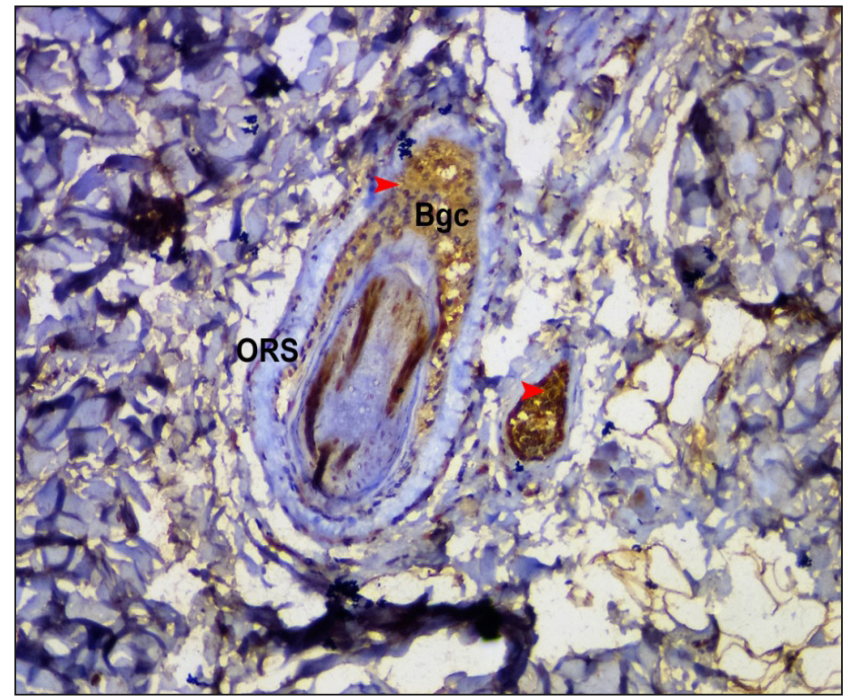

Fig. 3: Photomicrograph of cross section of canine hair follicle showing Cytokeratin 15 (CK15) positively stained cells (arrowheads) within the outer root sheath (ORS). $\times 200$ Bgc- Bulge cells ORS- Outer root sheath

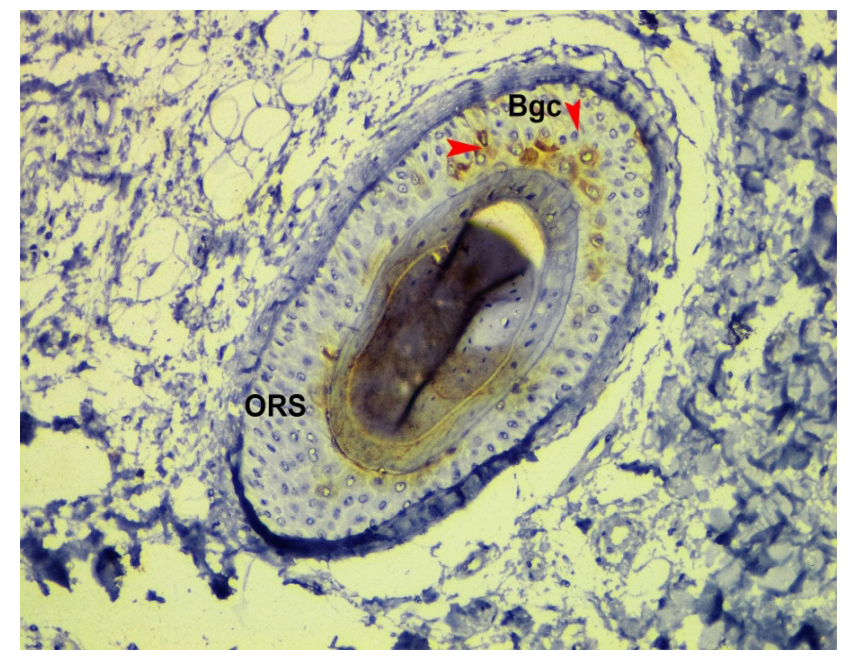

Fig. 4: Photomicrograph of cross section of canine hair follicle showing Cytokeratin 19 (CK19) positively stained cells (arrowheads) within the outer root sheath (ORS). $\times 200 \mathrm{Bgc}-$ Bulge cells ORS- Outer root sheath

Arrector pili muscle was also immunostained with smooth muscle actin (SMA) antibody which showed the insertion point of the muscle near the hair follicle which served as a landmark to locate the cluster of bulge cells in cross section of hair follicles (Fig. 5). Diverse protrusions in the bulge region of HF were filled with more densely packed 
ORS cells exclusively at the insertion point of arrectorpili muscle (APM) level and positively stained with CK15 surface marker (Fig. 6).

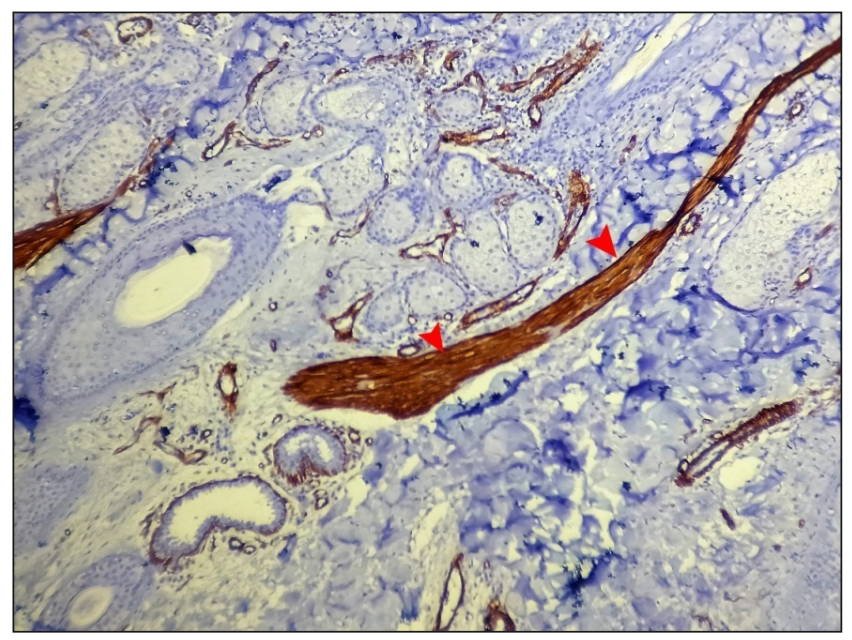

Fig. 5: Photomicrograph of arrectorpili muscle (APM) (arrowheads) immunostained with smooth muscle actin (SMA) antibody to earmark the location of the bulge region HF. $\times 100$

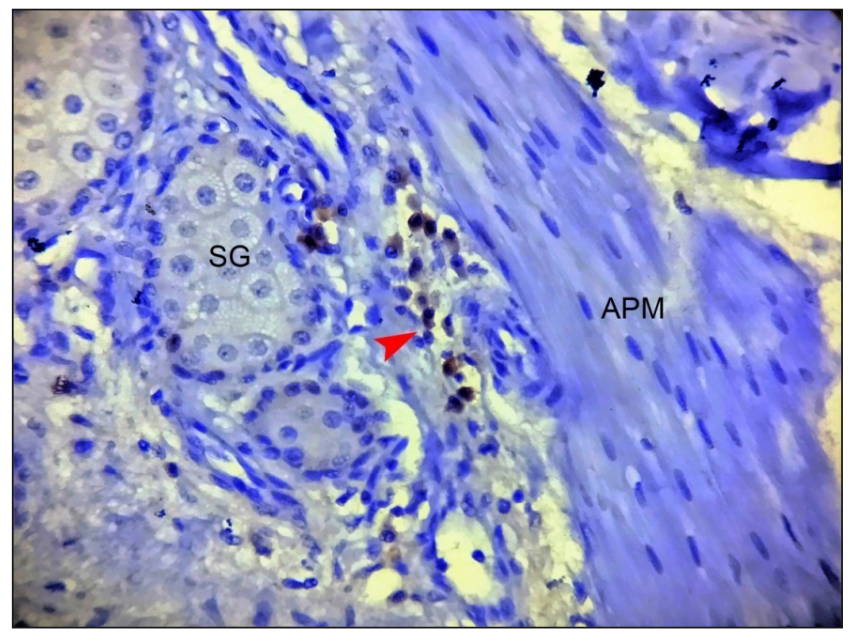

Fig. 6: Photomicrograph of canine hair follicle showing cytokeratin 15 (CK15) positively stained cHFSCs (arrowhead) near the insertion point of arrectorpilimuscle (APM). $\times 400$ APM- Arrectorpilimuscle SG- Sebaceous gland

ORS protrusions were reported in another study as follicular trochanter, observed at the point of APM insertion in humans (Tiede et al., 2007). This result also corroborates well with findings of Lyle et al. (1998) and Wang et al. (2012) in human.
In FITC conjugated Antibody staining, the CK15 positively stained cells were observed on the peripheral layer of outer root sheath of the hair follicle. The positive cells showed green fluorescent cytoplasm and blue fluorescent nucleus (Fig. 7). The bulge region of canine hair follicles were positively stained with CK19 and CK15 marker in the outermost layer of the ORS as reported by Commo et al. (2000) and Gho et al. (2004) who observed CK19 positive reaction in human $\mathrm{HF}$ and Kobayashi et al. (2009) reported CK15 positively in canine $\mathrm{HF}$.

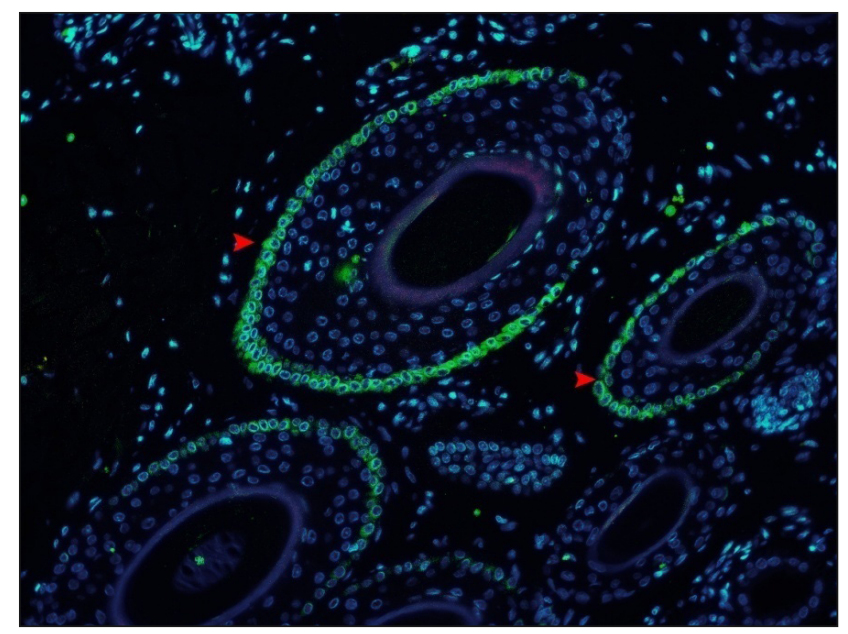

Fig. 7: Photomicrograph of cross section of canine hair follicle showing Cytokeratin 15 (CK15) positive stained cells with green fluorescence (arrowheads) located on the periphery of the outer root sheath $(\mathrm{ORS}) \times 200$

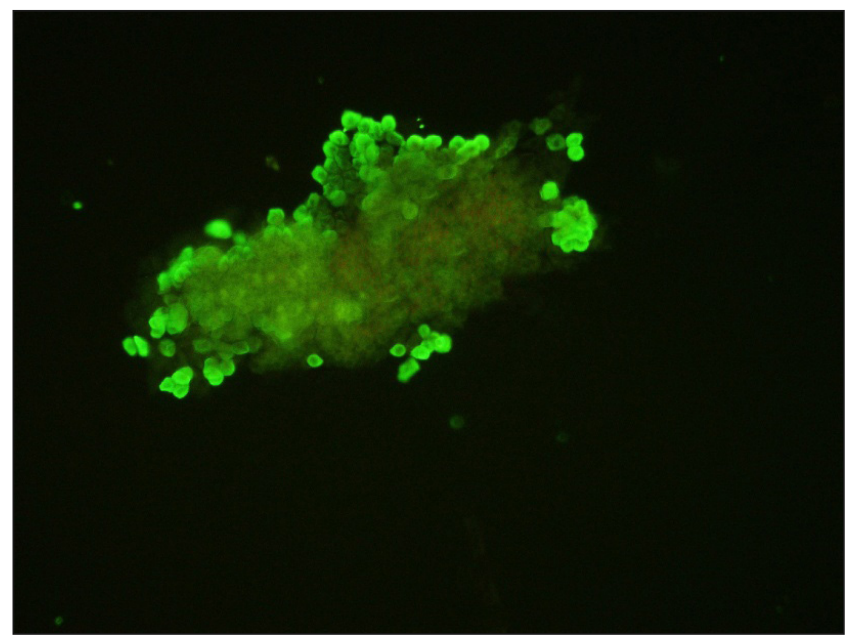

Fig. 8: Photomicrograph of cHFSCs derived from explant culture showing positive expression for Cytokeratin 15 (CK15) surface marker $\times 200$ 
Immunocytochemistry of isolated and cultured cells from canine hair follicle explants revealed positive expression of CK15 with green cytoplasmic fluorescence as per Kobayashi et al. (2009) (Fig. 8). According to Kloepper et al. (2008), CK15, CK19 and CD200 were the most useful positive surface markers for human bulge cells. Similar to the human scalp as demonstrated by Inoue et al. (2009), CK15 and CK19 expression was mostly found in peribulge and sub-bulge areas of the canine hair follicle in this study.

\section{ACKNOWLEDGEMENTS}

We are thankful to Dean, Madras Veterinary College, Chennai-07, for providing facilities and financial support during the entire research work. We acknowledge the Department of Surgery and Radiology for providing help during sample collection and Centre for Stem Research and Regenerative Medicine, Madras Veterinary College, for providing lab facilities to carry over the work.

\section{REFERENCES}

Alcolea, M.P. and Jones, P.H. 2014. Lineage analysis of epidermal stem cells. Csh. Perspect. Med., 4: a015206.

Bancroft, J. D. and Stevens, A. 1990. Theory and practice of histological techniques. No. 616.07583 T4, Edinburgh: Churchill Livingstone.

Commo, S., Gaillard, O. and Bernard, B.A. 2000. The human hair follicle contains two distinct K19 positive compartments in the outer root sheath: a unifying hypothesis for stem cell reservoir?. Differentiation, 66(4-5): 157-164.

Gho, C.G., Braun, J.E.F., Tilli, C.M.L.J., Neumann, H.A.M. and Ramaekers, F.C.S. 2004. Human follicular stem cells: their presence in plucked hair and follicular cell culture. $\mathrm{Br}$. $J$. Dermatol., 150: 860-868.

Hemavathi, N., Basha, S.H., Usha Kumary. S and Sivashankar. R. 2019. Culture methods for isolation of canine Hair Follicle Stem Cells (cHFSCs). Indian J. Vet. Anat., 31(2): 144-147.

Inoue, K., Aoi, N., Sato, T., Yamauchi, Y., Suga, Y., Eto, H., Kato, H., Araki, J. and Yoshimura, K. 2009. Differential expression of stem-cell-associated markers in human hair follicle epithelial cells. Lab. Investig., 89(8): 844.

Kloepper, E.J., Tiede, S., Brinckmann, J., Reinhardt, D.P., Meyer, W., Faessler, R. and Paus, R. 2008. Immunophenotyping of the human bulge region: the quest to define useful in situ markers for human epithelial hair follicle stem cells and their niche. Exp. Dermatol., 17(7): 592-609
Kobayashi, T., Iwasaki, T., Amagai, M. and Ohyama, M. 2010. Canine Follicle Stem Cell Candidates Reside in the Bulge and Share Characteristic Features with Human Bulge Cells. J. Investig. Dermatol., 130: 1988-1995.

Kobayashi, T., Shimizu, A., Nishifuji, K., Amagai, M., Iwasaki, T. and Ohyama, M. 2009. Canine hair-follicle keratinocytes enriched with bulge cells have the highly proliferative characteristic of stem cells. Vet. Dermatol., 20(5-6): 338-346.

Kobayshi, K., Rochat, A. and Barrandon, Y. 1993. Segregation of keratinocyte colony-forming cells in the bulge rat vibrissa. Proc. Natl. Acad. Sci., 90: 7391-7395.

Lyle, S., Christofidou-Solomidou, M., Liu, Y., Elder, D.E., Albelda, S. and Cotsarelis, G. 1998. The C8/144B monoclonal antibody recognizes cytokeratin 15 and defines the location of human hair follicle stem cells. J. Cell Sci., 111: 3179-3188.

Lyle, S., Christofidou-Solomidou, M., Liu, Y., Elder, D.E., Albelda, S. and Cotsarelis, S. 1999. Human Hair follicle Bulge Cells are biochemically distinct and possess an epithelial stem cell phenotype. J. Cell Sci., 4: 296-301.

Maleki, M., Ghanbarvand, F., Behvarz, M.R., Ejtemaei, M. and Ghadirkhomi, E. 2014. Comparison of mesenchymal stem cell markers in multiple human adult stem cells. Int. J. Stem. Cells, 7(2): 118 .

Ohyama, M., Terunuma, A., Tock, C.L., Radonovich, M.F., PiseMasison, C.A. Hopping, S.B., Brady, J.N., Udey, M.C. and Vogel, J.C. 2006. Characterization and isolation of stem cellenriched human hair follicle bulge cells. J. Clin. Investig., 116: $249-260$.

Purba, T.S., Haslam, I.S., Poblet, E., Jimenez, F., Gandarillas, A., Izeta, A. and Paus, R. 2014. Human epithelial hair follicle stem cells and their progeny: current state of knowledge, the widening gap in translational research and future challenges. Bioessays, 36(5): 513-525.

Schmidt-Ullrich, R. and Paus, R. 2005. Molecular principles of hair follicle induction and morphogenesis. Bioessays, 27(3): 247-261.

Tiede, S., Kloepper, J.E., Whiting, D.A. and Paus, R. 2007. The 'follicular trochanter': an epithelial compartment of human hair follicle bulge region in need of further characterization. Br. J. Dermatol., 157(5): 1013-1016.

Wang, X., Shi, Y., Zhou, Q., Liu, X., Xu, S. and Lei, T. 2012. Detailed histological structure of human hair follicle bulge region at different ages: a visible niche for nesting adult stem cells. J. Huazhong Univ. Sci. Technol. [Medical Sciences]., 32(5): 648-656. 
